\title{
Oesophageal tone in patients with achalasia
}

\author{
M González, F Mearin, C Vasconez, J-R Armengol, J-R Malagelada
}

\begin{abstract}
Background-The diagnosis and classification of oesophageal motility disorders is currently based on assessment of the phasic contractile activity of the oesophagus. Tonic muscular contraction of the oesophageal body (oesophageal tone) has not been well characterised. Aim-To quantify oesophageal tonic activity in healthy subjects and in patients with achalasia.

Patients-Oesophageal tone was measured in 14 patients with untreated achalasia and in 14 healthy subjects. In eight patients with achalasia, oesophageal tone was again measured one month after either endoscopic or surgical treatment.

Methods-Tonic wall activity was quantified by means of a flaccid intraoesophageal bag, $5 \mathrm{~cm}$ long and of $120 \mathrm{ml}$ maximal capacity, which was placed and maintained $5 \mathrm{~cm}$ above the lower oesophageal sphincter and connected to an external electronic barostat. The experimental design included measurement of oesophageal basal tone and compliance as well as the oesophageal tone response to a nitric oxide donor $(0.5 \mathrm{ml}$ amyl nitrite inhalation).

Results-Oesophageal basal tone, expressed as the intrabag (intraoesophageal) volume at a minimal distending pressure ( $2 \mathrm{~mm} \mathrm{Hg}$ ), did not differ significantly between patients with achalasia and healthy controls $(6.6(2.5) \mathrm{ml}$ versus 4.1 $(0.8) \mathrm{ml}$, respectively). Oesophageal compliance (volume/pressure relation during intraoesophageal distension) was significantly increased in achalasia (oesophageal extension ratio: $3.2(0.4) \mathrm{ml} / \mathrm{mm} \mathrm{Hg}$ versus $1.9(0.2) \mathrm{ml} / \mathrm{mm} \mathrm{Hg}$; $p<0.01)$. Amyl nitrite inhalation induced oesophageal relaxation both in patients and in controls, but the magnitude of relaxation was greater in the latter (intrabag volume increase: $15.3(2.4) \mathrm{ml}$ versus $36.2(7.1) \mathrm{ml}$; p<0.01).

Conclusion-In patients with achalasia, oesophageal tonic activity, and not only phasic activity, is impaired. Although oesophageal compliance is increased, residual oesophageal tone is maintained so that a significant relaxant response may occur after pharmacological stimulation. (Gut 1997; 41: 291-296)
\end{abstract}

Keywords: achalasia; oesophageal tonic activity; oesophageal barostat; amyl nitrite; NO donor

Achalasia is an oesophageal motor disorder that produces abnormal emptying of the oesophagus resulting in symptoms such as dysphagia and regurgitation. ${ }^{1}$ In most patients with achalasia there is no obvious aetiology, and the disease is rarely inherited. ${ }^{2}$ There are, however, several disorders that may mimic idiopathic achalasia, Chagas' disease and oesophagogastric carcinoma being the most important. ${ }^{34}$ Typical manometric findings in achalasia include both an abnormal relaxation pattern of the lower oesophageal sphincter (LOS), and disturbed oesophageal peristalsis. ${ }^{5}$ These abnormalities are probably responsible for the delayed oesophageal clearance observed in these patients. ${ }^{6}$ Recent studies have shown, in healthy subjects, that the oesophagus exerts an active tone contraction and that oesophageal tone can be modified by certain pharmacological agents. ${ }^{7}$ Nevertheless, in achalasia, only phasic motor activity of the oesophageal body has been evaluated; information concerning tonic activity is lacking.

We hypothesised that tonic, rather than exclusively phasic, motor activity of the oesophageal body may be altered in achalasia, and that disturbances in oesophageal tone may contribute to pathophysiological and clinical manifestations. From a theoretical point of view oesophageal tonic activity could be altered in two possible ways: increased tone due to increased cholinergic activation ${ }^{8}$ and decreased non-adrenergic, non-cholinergic inhibition ${ }^{9}{ }^{10}$; and diminished tone due to increased compliance, in itself secondary to oesophageal dilatation.

In the present report we describe the results obtained in 14 patients with idiopathic achalasia in whom oesophageal tone was quantified by an electronic barostat. Tone was evaluated at rest and also after pharmacological inhibition by a nitric oxide donor (amyl nitrite inhalation). In eight patients, measurements were performed before and one month after treatment of achalasia by either forceful endoscopic dilatation or surgical myotomy. A group of 14 healthy subjects was also studied for comparison.

\section{Methods}

SUBJECTS

Fourteen patients with symptomatic achalasia (eight women and six men; age range 34-71 years) were studied. The diagnosis of achalasia was substantiated by radiological, endoscopic, and manometric criteria. ${ }^{5}$ Patients met the following entry criteria: absence of diabetes mellitus, alcoholism, collagen vascular disorders, or neurological disease; no previous history of oesophageal, gastric, biliary, or oncological surgery; and no previous endoscopic or surgical treatment of their achalasia. Table 1 shows demographic data for each of the
Accepted for publication 2 May 1997 
TABLE 1 Demographic and laboratory data of patients with untreated achalasia

\begin{tabular}{|c|c|c|c|c|c|c|c|}
\hline $\begin{array}{l}\text { Case } \\
\text { No }\end{array}$ & Sex & Age (y) & $\begin{array}{l}\text { Symptom } \\
\text { duration } \\
\text { (months) }\end{array}$ & $\begin{array}{l}\text { Symptom } \\
\text { severity } \\
(D / P)\end{array}$ & $\begin{array}{l}\text { Maximal } \\
\text { oesophageal } \\
\text { diameter }(\mathrm{cm})\end{array}$ & $\begin{array}{l}\text { LOS } \\
\text { pressure } \\
\text { (mm } \mathrm{Hg})\end{array}$ & $\begin{array}{l}\text { Oesophageal } \\
\text { wave } \\
\text { amplitude } \\
\text { (mm Hg) }\end{array}$ \\
\hline 1 & $\mathrm{~F}$ & 35 & 60 & $4 / 3$ & 5.4 & 35 & 12 \\
\hline 2 & $\mathrm{~F}$ & 71 & 56 & $4 / 2$ & 3.7 & 35 & 35 \\
\hline 3 & $\mathrm{~F}$ & 34 & 108 & $3 / 2$ & 4.2 & 32 & 9 \\
\hline 4 & $\mathrm{~F}$ & 71 & 60 & $5 / 0$ & 4.5 & 27 & 17 \\
\hline 5 & M & 40 & 12 & $3 / 3$ & 3.9 & 17 & 15 \\
\hline 6 & $\mathrm{~F}$ & 41 & 72 & $4 / 3$ & 2.1 & 15 & 16 \\
\hline 7 & M & 69 & 8 & $3 / 1$ & 3.2 & 20 & 23 \\
\hline 8 & $\mathrm{~F}$ & 56 & 18 & $4 / 2$ & 2.7 & 24 & 10 \\
\hline 9 & M & 37 & 20 & $5 / 0$ & 2.6 & 48 & 14 \\
\hline 10 & $\mathrm{~F}$ & 38 & 18 & $5 / 2$ & 4.2 & 38 & 29 \\
\hline 11 & M & 34 & 18 & $4 / 1$ & 3.1 & 30 & 11 \\
\hline 12 & $M$ & 42 & 24 & $3 / 0$ & 3.5 & 24 & 17 \\
\hline 13 & $\mathrm{~F}$ & 25 & 32 & $5 / 0$ & 4.2 & 27 & 19 \\
\hline 14 & $\mathrm{M}$ & 46 & 84 & $5 / 0$ & 6.5 & 50 & 7 \\
\hline \multicolumn{2}{|c|}{ Mean (SE) } & $46(4)$ & $42(8)$ & $4 / 1$ & $3.8(0.2)$ & $30(3)$ & $17(2)$ \\
\hline
\end{tabular}

$\mathrm{D}$, dysphagia; $\mathrm{P}$, chest pain

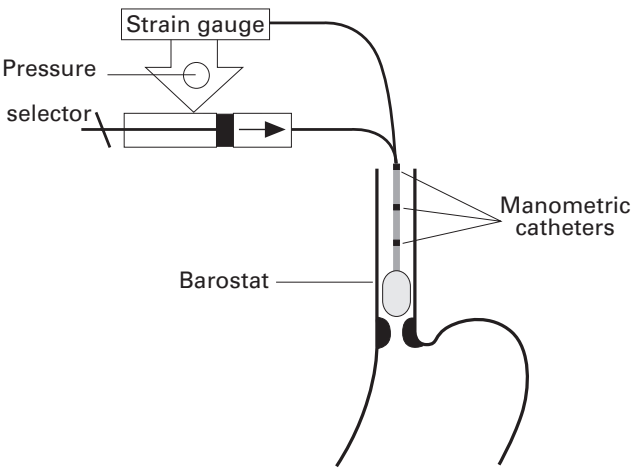

Figure 1: Schematic representation of the oesophageal barostat and three proximal manometric sites which allowed simultaneous recording of tonic and phasic oesophageal motility.

lateral opening and radially oriented openings spaced at $5 \mathrm{~cm}$ intervals along its distal portion. The tube was introduced orally, properly positioned, and the manometric catheters were then perfused continuously via a pneumohydraulic system. Respiration and swallowing were monitored using flexible bellows around the chest and neck, respectively. Oesophageal pressure activity was recorded on a paper polygraph (model 1600, MFE Corporation, Salem, New Hampshire, USA). Studies were performed in the supine position and LOS pressure was evaluated by the pull-through technique.

In every subject we performed on separate a standard oesophageal manometry study and measurement of oesophageal tone. All studies began in the morning after an overnight fast. Patients had taken no medication for at least 48 hours previously. Eight patients with achalasia were also studied one month after treatment: forceful endoscopic dilatation in six patients and surgical myotomy in two patients. Clinical assessment and barium swallow evaluation of the oesophagus were also performed before and one month after treatment, as specified below.

CLINICAL ASSESSMENT

Patients underwent complete history and physical examination by one of the investigators (FM). Oesophageal symptoms, including dysphagia to liquids and solids, chest pain, and heartburn were quantified before and after treatment according to the following score: 0 , never; I, less than once a month; 2, monthly; 3, weekly; 4, daily; and 5, with every meal or more than three times a day.

\section{RADIOLOGICAL EVALUATION OF OESOPHAGEAL} DIAMETER

An oesophagogram using a standard radiological method with barium contrast was obtained in every patient. The diameter of the oesophageal body $5 \mathrm{~cm}$ above the gastrooesophageal junction was measured in the antero-posterior projection and the highest value registered. A correction factor to obtain the real oesophageal diameter value from the diameter measured in $x$ ray films was used.

OESOPHAGEAL MANOMETRY

Oesophageal intraluminal pressures were measured using a four lumen polyvinyl tube (0.9 $\mathrm{mm}$ internal diameter of each lumen) with
QUANTIFICATION OF OESOPHAGEAL TONE AND COMPLIANCE

An electronic barostat was used to measure oesophageal tone. The barostat measures the volume of air within an intra-oesophageal bag that is maintained at a constant preselected pressure level by an electronic feedback mechanism. The latter consists of a strain gauge linked by an electronic relay to an air injectionaspiration system (fig 1). A dial in the electronic systems allows selection of a pressure level. When the pressure detected by the strain gauge falls $0.25 \mathrm{~mm} \mathrm{Hg}$ below the selected pressure, the system injects air until the pressure is corrected; conversely, a pressure rise triggers the air aspiration system. A detailed description of the electronic barostat has been published previously. ${ }^{11}{ }^{12}$

The oesophageal barostat was connected by a double lumen polyvinyl tube (French No. 12, Argyle, Sherwood Medical, St Louis, Missouri, USA) to an ultrathin polyethylene bag, $5 \mathrm{~cm}$ in length, with a maximum diameter of $12 \mathrm{~cm}$ and were attached to the connecting tube of the barostat. They were placed at 5,10 , and $15 \mathrm{~cm}$ from the middle point of the barostat bag and served to record oesophageal phasic activity (fig 1). Both tonic and phasic oesophageal pressure activities were recorded by a paper polygraph (model 1600, MFE Corporation).

To quantify oesophageal tone the barostat bag, finely folded, was inserted orally and positioned $5 \mathrm{~cm}$ above the LOS (previously located by manometry). To unfold the intraoesophagic bag one lumen of the connecting tube was connected to a pressure transducer and the bag $120 \mathrm{ml}$ capacity. Three manometric catheters 
was slowly inflated through the other lumen of the tube with $30 \mathrm{ml}$ of air. The bag was then completely deflated and connected to the barostat. Participants were placed in a $30^{\circ}$ from horizontal recumbent position and were asked to relax comfortably, while pressure and volume inside the intraoesophagic bag were continuously recorded on a paper polygraph. The following parameters were quantified: oesophageal basal tone, oesophageal compliance, and oesophageal tone in response to a nitric oxide donor (amyl nitrite inhalation).

Using the pressure-selection dial of the barostat, intrabag pressure was gradually increased by $2 \mathrm{~mm} \mathrm{Hg}$ stepwise increments every two minutes, until $20 \mathrm{~mm} \mathrm{Hg}$ was reached or whenever participants expressed discomfort. Perception was scored at each pressure step using a rating scale graded from 0 to 10 .

Amyl nitrite inhalation $(0.5 \mathrm{ml})$ was administered to assess the effect of a smooth muscle relaxant on oesophageal tone. Amyl nitrite was inhaled for 45 seconds and the balloon volume was measured before and during inhalation. The effect of amyl nitrite was assessed during constant distension of the oesophageal body at $7 \mathrm{~mm} \mathrm{Hg}$. Heart rate was monitored before and at the end of amyl nitrite inhalation.

DATA ANALYSIS

Oesophageal manometry

Resting LOS pressure was determined by the station pull-through technique using intragastric pressure as the zero reference. The mean (SE) of the eight values obtained during two pull-throughs of the four lumen catheter was calculated. Oesophageal peristalsis and LOS relaxation were assessed after a minimum of ten $5 \mathrm{ml}$ water swallows.

\section{Oesophageal basal tone}

This represents the resistance of the oesophageal wall to initial stretch, and was determined at rest as the intrabag volume obtained at the minimal distending pressure evaluated $(2 \mathrm{~mm} \mathrm{Hg})$

\section{Oesophageal compliance}

This represents the relation between intraluminal pressure applied by the barostat and average intrabag volume obtained at each pressure level. Volumes at each pressure level were corrected for air compressibility using Boyle's law $\left(\mathrm{P}_{1} \mathrm{~V}_{1}=\mathrm{P}_{2} \mathrm{~V}_{2}\right)$. A compliance curve was then constructed and values expressed also as the extension ratio. The extension ratio is a single value that corresponds to the mean volume/pressure ratio for each of the different distending pressures tested.

\section{Oesophageal tone in response to amyl nitrite}

In this test we measured the maximal intraoesophageal volume for one minute after the onset of the pharmacological stimulus. The change was calculated as the difference between this value and the basal value (average of intra-oesophageal volume during the five minutes that preceded the stimulus). It was also expressed as the change in oesophageal diam-

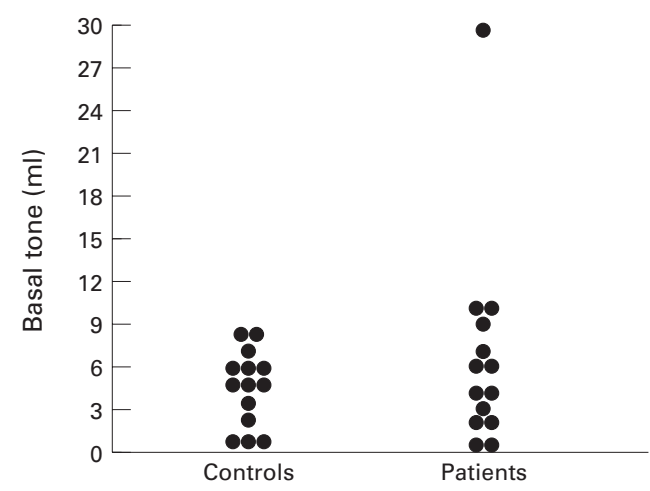

Figure 2: Oesophageal basal tone (intrabag volume at the minimal distending pressure: $2 \mathrm{~mm} \mathrm{Hg}$ ) in healthy controls and untreated patients with achalasia.

eter induced by the stimulus. Oesophageal diameter was calculated assuming a cylindrical shape for the expanded oesophageal balloon and knowing at all times both the intraballoon volume (v) and the balloon length (1) (constant: $5 \mathrm{~cm})$. Thus, oesophageal diameter $=$

$$
\left(\sqrt{\frac{\mathrm{v}}{1 \times \pi}}\right) \times 2
$$

STATISTICAL ANALYSIS

For each group of participants we calculated mean (SE) values obtained for each parameter. Statistical comparisons were performed using Student's $t$ test for normally distributed data, with a paired analysis for intragroup comparisons and unpaired analysis for intergroup comparisons. The Mann-Whitney U test was used for non-normally distributed data. To elucidate possible correlations between specific parameters we performed linear regression analysis. For all tests, values of $p<0.05$ were considered significant.

\section{Results}

Table 1 shows clinical and laboratory data for the 14 patients with achalasia in the study. All patients had severe symptoms (grades 3-5 for dysphagia). Oesophageal diameter on the oesophagogram was larger than $2.5 \mathrm{~cm}$ in all but one patient. As expected, oesophageal manometry showed a resting LOS pressure that was significantly higher than in controls (30 (3) $\mathrm{mm} \mathrm{Hg}$ versus 18 (2) $\mathrm{mm} \mathrm{Hg}$; $\mathrm{p}<0.05)$. Oesophageal wave amplitude during swallowing was also significantly lower in patients $(17$ (2) $\mathrm{mm} \mathrm{Hg}$ ) than in controls (64 (8) $\mathrm{mm} \mathrm{Hg})(\mathrm{p}<0.05)$.

Oesophageal basal tone was similar in patients with untreated achalasia and in healthy controls (fig 2). Thus, intrabag volume at minimal distending pressure $(2 \mathrm{~mm} \mathrm{Hg})$ was $6.6(2.5) \mathrm{ml}$ in patients and $4.1(0.8) \mathrm{ml}$ in controls.

Oesophageal compliance was greater in patients with untreated achalasia than in healthy subjects (fig 3). Consequently, the oesophageal extension ratio was much higher in patients with untreated achalasia (3.2 (0.4) 


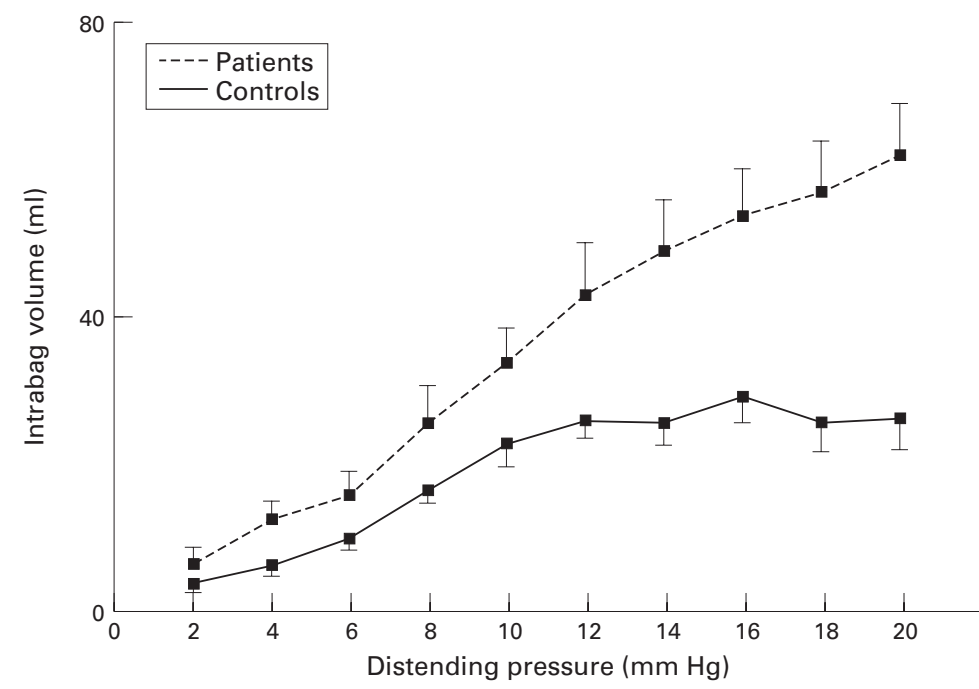

Figure 3: Increase in oesophageal compliance in patients with achalasia: higher volumes were obtained at similar distending pressures $(p<0.05$ versus controls for cumulative values and slope) (means (SE)).

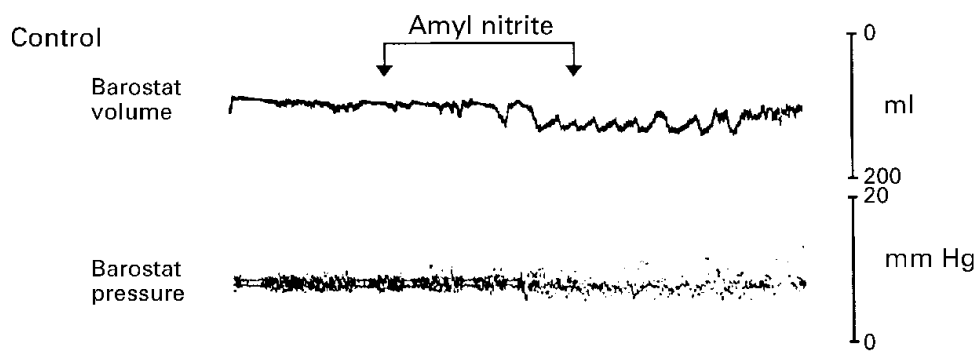

Patient

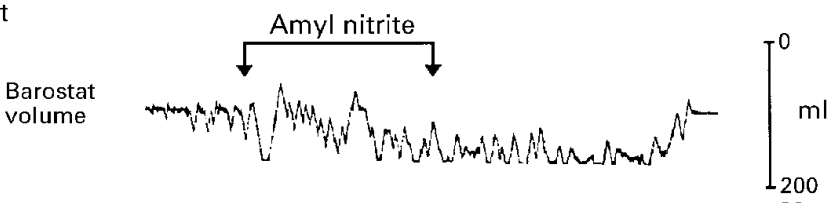

Barostat
pressure

Figure 4: Actual tracing illustrating the relaxant effect of amyl nitrite inhalation on the oesophageal body (increase in intra-oesophageal volume) both in controls and patients. The magnitude of the relaxant response was larger in the patients.

TABLE 2 Oesophageal and cardiac responses to amyl nitrite inhalation

\begin{tabular}{|c|c|c|c|}
\hline & \multirow[b]{2}{*}{$\begin{array}{l}\text { Healthy controls } \\
(n=14)\end{array}$} & \multicolumn{2}{|c|}{ Patients with achalasia } \\
\hline & & $\begin{array}{l}\text { Before treatment } \\
(n=14)\end{array}$ & $\begin{array}{l}\text { After treatment } \\
(n=8)\end{array}$ \\
\hline Intra-oesophageal volume increase $(\Delta \mathrm{ml})$ & $15.3(2.4)$ & $36.2(7.1)^{\star}$ & $32.7(6.8)^{\star}$ \\
\hline Oesophageal diameter increase $(\Delta \mathrm{ml})$ & $0.86(0.2)$ & $1.53(0.5)^{\star}$ & $1.36(0.4)^{\star}$ \\
\hline Heart rate increase $(\Delta \mathrm{bpm})$ & $26(3)$ & $24(2)$ & $22(3)$ \\
\hline Duration of oesophageal relaxation (s) & $62(5)$ & $67(9)$ & $64(5)$ \\
\hline
\end{tabular}

Results expressed as mean (SE).

${ }^{\star} \mathrm{p}<0.05 v$ healthy controls.

$\mathrm{ml} / \mathrm{mm} \mathrm{Hg}$ ) than in controls (1.9 (0.2) $\mathrm{ml} /$ $\mathrm{mm} \mathrm{Hg})(\mathrm{p}<0.01)$.

During the procedure to measure oesophageal compliance, which involves stepwise oesophageal distension, none of the patients with achalasia and only one of the healthy subjects complained of oesophageal pain. In this particular subject discomfort was scored as 8 and appeared at a distending pressure of $16 \mathrm{~mm} \mathrm{Hg}$ with an intrabag volume of $23 \mathrm{ml}$.

OESOPHAGEAL TONE IN RESPONSE TO A NITRIC

OXIDE DONOR

Amyl nitrite inhalation significantly reduced oesophageal tone both in healthy volunteers and in patients with achalasia (fig 4 and table 2). Intrabag (intra-oesophageal) volume increased by $15.3(2.4) \mathrm{ml}$ in controls and by $36.2(7.1) \mathrm{ml}$ in patients $(\mathrm{p}<0.01)$; estimated oesophageal diameter increased by $0.86(0.2) \mathrm{cm}$ in controls and $1.53(0.5) \mathrm{cm}$ in patients $(\mathrm{p}<0.05)$. Drug inhalation increased the heart rate to a similar extent in controls (26 (3) bpm) and in patients (24 (2) bpm). Both the oesophageal relaxatory response and the tachycardia lasted for less than 100 seconds (table 2).

Oesophageal basal tone, quantified by the barostat, was unrelated to maximal oesophageal diameter, measured on the oesophagogram. The radiological oesophageal diameter was, however, significantly correlated with both oesophageal compliance, expressed as the extension ratio $(r=0.58 ; \mathrm{p}=0.02)$ and with maximal intrabag volume, obtained in each patient at the maximal distending pressure $(r=0.71 ; \mathrm{p}=0.003)$. The oesophageal relaxation induced by amyl nitrite was not significantly related to the diameter of the oesophagus measured on the oesophagogram. Moreover, no correlation was found between the magnitude of the relaxant response to amyl nitrite and either oesophageal compliance (calculated as the extension ratio), maximal intrabag volume (maximal volume obtained in each patient during oesophageal distension), or autonomic response (increase in heart rate).

No significant correlations were identified among oesophageal tone and manometric variables-LOS resting pressure, intraoesophageal resting pressure, or oesophageal wave amplitude. Likewise, no correlation was found between scored clinical symptoms and either oesophageal basal tone, compliance, or relaxation induced by amyl nitrite. They were of similar magnitude in patients with clinically relevant chest pain (grades $2-3 ; n=7$ ) and those without chest pain (grades $0-1 ; n=7$ ).

\section{EFFECT OF TREATMENT}

One month after endoscopic or surgical treatment all patients were clinically improved and their dysphagia scores fell to grades $0-2$. Oesophageal diameter on the oesophagogram also decreased to a mean of $3.5(0.4) \mathrm{cm}$.

No significant differences in basal tone were detected by comparing before and after treatment values (volume at minimal distending pressure: $6.7(2.5) \mathrm{ml})$. Oesophageal compliance curves were also similar before and after treatment (fig 5). Moreover, after treatment, oesophageal relaxation induced by amyl nitrite was similar to that before treatment (32.7 (6.8) $\mathrm{ml}$ ) (table 2).

After treatment of achalasia, contrary to pretreatment results, radiological oesophageal diameter was unrelated to oesophageal compli- 


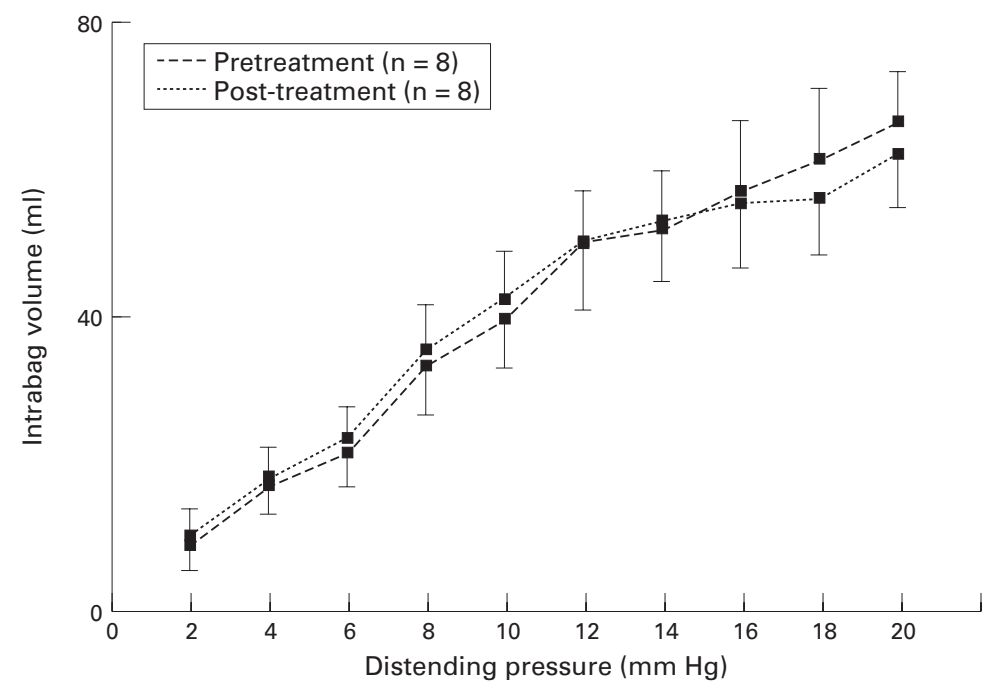

Figure 5: In patients with achalasia, oesophageal compliance remained unchanged one month after treatment (means (SE)).

ance, maximal intrabag volume, or magnitude of oesophageal relaxation induced by amyl nitrite.

\section{Discussion}

Until recently, oesophageal motor disturbances were exclusively evaluated by measurement of phasic oesophageal motility by manometry and oesophageal tone was overlooked. This situation was primarily attributable to lack of an appropriate method for measuring oesophageal tone. The development of the electronic barostat, initially applied to measurement of gastric tone, permitted assessment of tonic activity at different levels of the gut, including the oesophagus. $^{711-15}$ Using a barostat system, Mayrand and Diamant first demonstrated in vivo that the smooth muscle region of the human oesophagus exerts active tonic contraction, and that oesophageal tone may be decreased by smooth muscle relaxants. ${ }^{7}$ These results have been confirmed and extended by the present study.

We hypothesised that oesophageal motor disorders which characteristically affect phasic activity of the oesophageal body would also affect the tonic component of oesophageal motility. Moreover, whether phasic and tonic motility abnormalities coexisted or occurred separately had to be established. In the present study we focused on a group of patients with achalasia and found that oesophageal tonic activity, and not only phasic activity, was impaired. However, substantial tonic activity remained as the achalasic oesophagus was still able to relax significantly in response to amyl nitrite. Our findings ${ }^{16}$ and similar results obtained by Bzowej et $a l^{17}$ were recently published in abstract form. In our study, oesophageal relaxation induced by a nitric oxide donor was significantly greater in patients with achalasia than in healthy subjects. Such an effect could be explained either by an abnormal hypersensitive response to exogenous nitric oxide or by a normal relaxatory response of a more compliant oesophagus. With respect to the first point, it is known that nitric oxide participates in the physiological control of oesophageal motility as a major inhibitory neurotransmitter, ${ }^{18}$ that nitric oxide synthase is absent in the gastro-oesophageal junction muscle of patients with achalasia, and that oesophageal muscle strips obtained from patients with achalasia are able to relax when exposed to sodium nitroprusside (another nitric oxide donor). ${ }^{10}$ On the other hand, it may be also postulated that the magnitude of the oesophageal relaxation was increased because in achalasia both oesophageal diameter and oesophageal compliance are increased. In our analysis, however, oesophageal relaxation induced by amyl nitrite seemed to be unrelated to oesophageal diameter or compliance, whether in treated or untreated patients. The number of patients was, however, relatively small and a type II error cannot be excluded. Whatever the case - nitric oxide hypersensitivity or increased compliance-even the severely achalasic oesophagus preserves a substantial resting tone and hence does not behave as a flaccid sac as might have been anticipated.

In the present study we also evaluated the effect of achalasia treatment, endoscopic and surgical, on oesophageal tone. It is known that treatment is usually of little consequence to phasic oesophageal motility as, in most patients, oesophageal aperistalsis persists and the amplitude of the oesophageal waves does not change. In about $25-30 \%$ of cases some peristalsis appears after endoscopic dilatation, ${ }^{19}$ surgical myotomy, ${ }^{20}$ and even drug therapy. ${ }^{21}$ The clinical significance of posttreatment restoration of even partial peristaltic activity is unclear. With respect to the effect of treatment on tonic activity, it is possible that the post-treatment fall in gastro-oesophageal junction resistance and consequent "decompression" of the oesophagus could facilitate recovery of oesophageal tone and compliance. Since a hypercompliant oesophagus pretreatment and the resulting "common cavity" effect may be responsible for the manometric appearance of aperistalsis, ${ }^{22}$ recovery of tone posttreatment could explain the reappearance of peristaltic activity, as observed in some patients. Nevertheless, in our study oesophageal basal tone and compliance remained unchanged one month after treatment. Possibly one month is too short an interval to allow recovery of oesophageal wall contractile activity. Although in the present study we have been unable to prove a direct relation between persistent symptoms and tonic changes, it is conceivable that more prolonged observation of a larger group of patients might have produced such a relation. Further studies should be conducted to explore the role of oesophageal tone on clinical manifestations of achalasia before and after treatment.

During oesophageal isobaric balloon distension none of our 14 patients with achalasia perceived chest pain even though in most cases intrabag volumes exceeded $80 \mathrm{ml}$ and oesophageal diameters extended over $5 \mathrm{~cm}$. The apparent lack of conscious perception of the studied oesophageal wall could be attributable to a visceral perceptive defect coexisting 
with the motor disorder to the increased compliance, which would preclude the increase in oesophageal wall tension necessary to stimulate sensitive mechanoreceptors.

In summary, tonic as well as phasic contractility of the oesophageal body is altered in patients with achalasia. However, significant resting tone is maintained as manifested by a significant relaxant response to administration of a nitric oxide donor. One month after treatment (either endoscopic dilatation or surgical myotomy), oesophageal basal tone, compliance, and relaxation induced by pharmacological stimulation remained unchanged. These preliminary observations suggest that oesophageal tone and compliance are modified by achalasia. However, additional studies are required to elucidate the subsequent course of tonic activity after treatment and the relevance of changes in oesophageal tone in the clinical manifestations that may persist after otherwise successful LOS dilatation or myotomy.

1 Cohen S. Motor disorders of the esophagus. $N$ Engl f Med 1979; 301: 184-92.

2 Frieling T, Berges W, Borchard F, Lubke HJ, Enck P, Wienbeck $M$. Family occurrence of achalasia and diffuse spasm of the oesophagus. Gut 1988; 29: 1595-602. 3 Betarello A, Pinotti WH. Esophageal involvement in

4 Kahrilas PJ, Kishk SM, Helm JF, Dodds WJ, Harig JM, Hogan WJ. Comparison of pseudoachalasia and achalasia. Am 7 Med 1987; 82: 439-46.

5 Vantrappen G, Hellemans J. Achalasia. In: Vantrappen G, Hellemans J, eds. Diseases of the esophagus. Berlin: Springer

6 Robertson CS, Hardy JG, Atkinson M. Quantitative assessment of the response to therapy in achalasia of the cardia Gut 1989; 30: 768-73.

7 Mayrand S, Diamant NE. Measurement of human esophageal tone in vivo. Gastroenterology 1993; 105: 1411-20.
8 Holloway RH, Dodds WJ, Helm JF, Hogan WJ, Dent J, Arndorfer RC. Integrity of cholinergic innervation to the lower esophageal

9 Aggestrup S, Uddman R, Sundler F, Fahrenkrug J, Hakanson R, Sorensen HR, Hambraeus G. Lack of vasoactive intestinal polypeptide nerves in esophageal achalasia. Gastroenterology 1983; 84: 924-7.

10 Mearin F, Mourelle M, Guarner F, Salas A, RiverosMoreno V, Moncada S, Malagelada J-R. Patients with achalasia lack nitric oxide synthase in the gastroachalasia lack nitric oxide synthase in the gastro-

11 Azpiroz F, Malagelada J-R. Physiologic variations in canine gastric tone measured by an electronic barostat. $A m$ f Physiol 1985; 248: G229-37.

12 Mearin F, Cucala M, Azpiroz F, Malagelada J-R. The origin of symptoms on the brain-gut axis in functional dyspepsia. Gastroenterology 1991; 101: 999-1006.

13 Rouillon JM, Azpiroz F, Malagelada J-R. Sensorial and intestino-intestinal reflex pathways in the human jejunum. Gastroenterology 1991; 101: 1006-12.

14 Sims MA, Hasler WL, Chey WD, Kim MS, Owyang Ch. Hyperglycemia inhibits mechanoreceptor-mediated gastroHyperglycemia inhibits mechanoreceptor-mediated gastro-
colonic responses and colonic peristaltic reflexes in healthy colonic responses and colonic peristaltic reflexe
humans. Gastroenterology 1995; 108: 350-9.

15 Mertz H, Naliboff B, Munakata J, Niazi N, Mayer EA. Altered rectal perception is a biological marker of patients with irritable bowel syndrome. Gastroenterology 1995; 109: $40-52$.

16 Gonzalez M, Mearin F, Baudet S, Malagelada J-R. Esophageal wall tone in patients with achalasia [abstract]. Gastroenterology 1995; 108: A607.

17 Bzowej NH, Mayrand S, Diamant NE. Esophageal tone and compliance in achalasia [abstract]. Gastroenterology 1995; 108: A578.

18 Tottrup A, Svane D, Forman A. Nitric oxide mediating NANC inhibition in opossum lower esophageal sphincter. Am f Physiol 1991; 260: G385-9.

19 Mellow MH. Return of esophageal peristalsis in idiopathic achalasia. Gastroenterology 1976; 70: 1148-51.

20 Ponce J, Miralbés M, Garrigues V, Berenguer J. Return of esophageal peristalsis after Heller's myotomy for idiopathic achalasia. Dig Dis Sci 1986; 31: 545-7.

21 Coccia G, Bortolotti M, Massa P, Michetti P, Dodero M. Return of esophageal peristalsis after sublingual nifedipine in achalasia patients [abstract]. Gastroenterology 1991; 100: in achar.

22 Parrilla P, Aguayo JL, Martínez de Haro LF, Ortiz A. Reversible achalasia-like motor pattern of esophageal body secondary to postoperative stricture of esophageal junction. Dig Dis Sci 1992; 37: 1781-4. 